\title{
THE INTERDEPENDENCE OF ANIMAL INTAKE, PRE-AND POST-GRAZING PASTURE MASS AND STOCKING DENSITY
}

D. G. MCCALL, R. J. TOWNSLEY', J. S. BIRCHAM ${ }^{2}$, G. W. SHEATH. Whatawhata Hill Country, Research Station,

MAF, Hamilton.

'Massey University, Palmerston North. 2P.O. Box 1312. Hamilton.

ABSTRACT

A simple version of the model validated by Bricham et al (1985) was used to illustrate the factors affecting average daily intake of animals under different grazing conditions. The model accounts for differences in pre-grazing pasture mass and grazing pressure in describing pasture disappearance through time under grazing.

Analyses based on the model showed the interdependencies between intake and pre-and post-grazing pasture mass and grazing pressure. In ewes grazing to a common residual $(400 \mathrm{~kg}$ $\mathrm{GDM} / \mathrm{ha}$ ) intake varied between 1.32 and $0.75 \mathrm{~kg} \mathrm{GDM} / \mathrm{h} /$ day where pre-graze mass varied between 2500 and $1000 \mathrm{~kg}$ GDM/ha. It was concluded that where the objective of grazing management is to control animal intake at any level, attention must be paid to pre-grazing pasture mass in setting target residuals. Appropriate residuals and grazing pressures to achieve target intakes can readily be assessed for any pre-graze mass using the model presented. Keywords: Pasture mass, animal intake, pre-graze mass, residual, grazing pressure, stocking density, model, feed budget.

\section{INTRODUCTION}

Farmers and advisers involved in feed budgeting exercises need to know pasture conditions required to achieve given animal feed requirements. Meeting requirements is critical to the achievement of both target animal growth rates and successful allotation of feed.

Pasture mass has been shown to decline at a decreasing exponential rate through time during grazing (Sheath 1983) (Fig. la). Intake is therefore not constant over a range of pasture masses but declines as mass declines (Fig lb).

A model (equation 1) which describes pasture mass levels, and hence disappearance of pasture under both sheep and cattle grazing has been validated by Bricham et al. (1985).

$$
Y_{t}=Y_{o} e^{-k n t} \ldots \ldots \ldots \ldots \ldots
$$

This model predicts $Y_{t}$, the residual green pasture mass (GDM/ha) after $n$ animals have been grazing a hectare for $t$ days, and where the initial or pre-grazing green pasture mass was $Y_{0}$. The value of the constant $K$ in the model is likely to vary with the maximum intake of the stock class involved. Maximum intake for any class of stock will in turn vary with their physiological state, and liveweight in the case of young growing animals. Other factors may also affect the value of $\mathrm{K}$ and these are discussed in full by Bricham et al. (1985).

Two important assumptions must hold for the model as presented above to apply. The first assumption is that there is no growth of green pasture over the period of time a given area is being grazed. Where t is small, that is less than 4 or 5 days, and pasture growth rate is low or stocking density is high, this assumption is not likely to result in serious underestimation of animal intake and/or overestimation of residual. The second condition on the model as presented above is that animal intake on any day during the grazing interval must be less than or equal to the maximum daily intake.

Given the above provisos, this model can readily be used to illustrate factors 

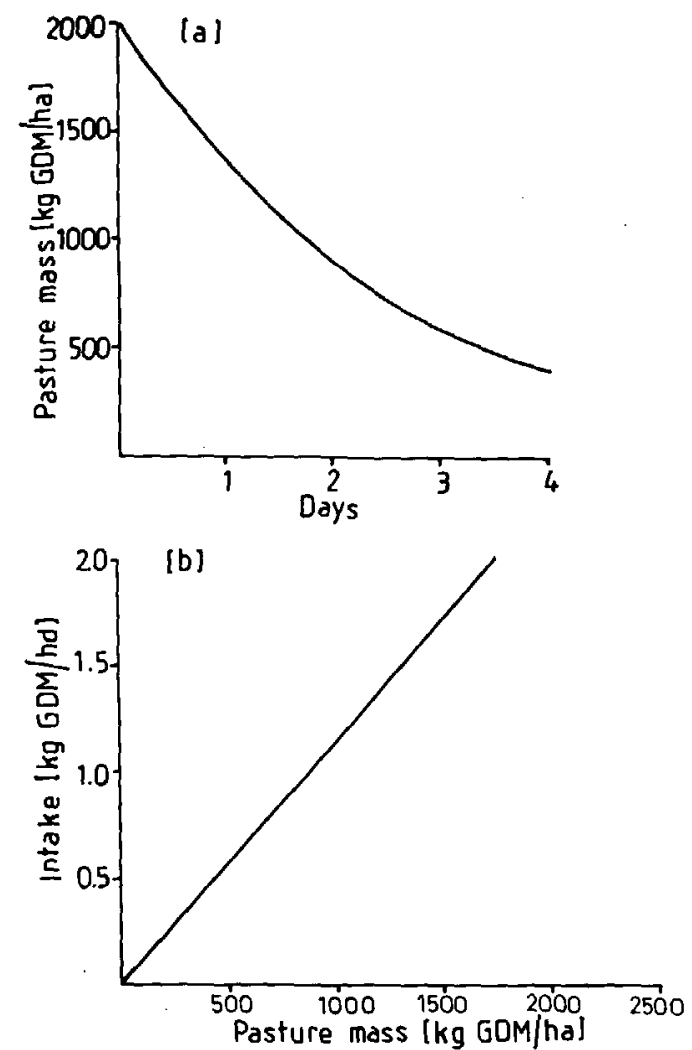

FIGURE 1: (a) typical decline in green pasture mass under rotational grazing; and (b) the effect of green pasture mass on intake.

affecting average daily intake (ADI) of animals under different grazing conditions.

In the present paper effects of, 1), pre-grazing pasture mass on intake of ewes grazing to a common residual and, 2), condiitons required to achieve a feed requirement of $1 \mathrm{~kg} \mathrm{DM} / \mathrm{h} /$ day are investigated. In simple feed budgeting, target intakes and associated target residuals are set to determine time spent grazing a paddock. Possible errors associated with this approach are also studied.

Analyses based on the model suggest that the concept of predicting the achievement of animal feed requirements from residual pasture mass is likely to need modification to account for pre-grazing pasture mass levels.

\section{Assumptions}

\section{EXAMPLES OF MODEL USE}

The model was used to evaluate the effectiveness of a number of criteria commonly used to achieve given feed requirements by a rotationally grazed ewe mob. Mature ewes have a maximum daily GDM intake of about $2 \mathrm{~kg}$ (Rattray and Clark 1984). The value of $\mathrm{K}$ for a ewe with a maximum intake of $2 \mathrm{~kg}$ GDM/day was assumed to be 0.00115 . This assumption does not affect the principles illustrated and the rationale for the choice of value is presented in Appendix I.

In applying the model it must be remembered that the model as presented holds only 


\section{APPENDIX 1}

Derivation of Value of $K$ for breeding ewes

The value for $\mathrm{K}$ in the pasture disappearance model of functional form:

$Y_{t}=Y_{0} e^{-k n t}$

was derived for ewes using the following information.

1 When pasture accessibility is not limiting, maximum intake (MI) can be achieved by offering animals an allowance of 4 times their Ml (Hodgson, 1975). Ninety per cent of Ml is achieved at an allowance of two times $\mathrm{Ml}$.

2. Adult sheep grazed at high pasture allowances need pre-graze pasture masses in the order of 2000 $\mathrm{kg} \mathrm{GDM} /$ ha if intake is not to be restricted (Bircham et al. 1985).

3. MI for adult sheep is about $2 \mathrm{~kg} \mathrm{GDM} / \mathrm{hd}$ (Rattray and Clark, 1984).

4.

$\begin{aligned} \text { Where } t & =1 \\ \mathrm{Y}_{0} & =2000 \\ \mathrm{Ml} & =2 \\ \text { and Allowance } & =4 \times \mathrm{MI} \\ \text { then } \mathrm{n} & =\mathrm{Y}_{0} / \text { Allowance } \\ \text { and } \mathrm{Yt} & =250 \\ \mathrm{k} & =\mathrm{Y}_{0} \cdot(\mathrm{n} \times \mathrm{MI}) \\ & =1500 \\ & =\left(\ln \mathrm{Y}_{\mathrm{t}} \ln \mathrm{Y}_{0}\right) / \mathrm{nt} \\ & =(\ln 1500 \cdot \ln 2000) / \mathrm{nt} \\ & =0.00115\end{aligned}$

In is the natural logarithm.

where daily intake is less than maximum intake on any day. At a stocking density of $n$ ewes per hectare, intake per ewe on the first day $\left(I_{l}\right)$ of grazing a break is given by the model as:

$$
I_{1}=Y_{0}\left(1-e^{-k n}\right) / n \text {. . . . . . . . . . . } 2
$$

Given maximum intake is $2 \mathrm{~kg}$ GDM/day, ewes stocked at a density of $\mathrm{n}$ ewes per hectare will achieve maximum intake on the first day of a grazing break at a pre-grazing mass $\left(Y_{0}\right)$ where:

as shown in Table 1.

$$
Y_{0}=2 n /\left(1 \cdot e^{-k n}\right) \cdot . \cdot . \cdot . \cdot . \cdot . \cdot .3
$$

In the above instance the model therefore applies only where:

$$
Y_{0} \leq 2 \mathrm{n} /\left(1-e^{-k n}\right)
$$

This is the area below the line in Figure 2.

Where pre-grazing mass (Yo) for any given stocking density is greater than that indicated by the relationship in Figure 2, intake would in reality not be restricted on that day and would equal maximum intake.

Application of the model to individual situations also requires knowledge of the values of the parameters $\mathrm{n}$ and $\mathrm{t}$. Because many farmers and advisers conceive grazing management in terms of rotation length it is worth noting the following relationships between the parameters $\mathrm{n}$ and $\mathrm{t}$ in the model and such variables as:

rotation length

total area involved in the rotation (A)

area of the break grazed by the mob for t days (a)

mob size $(\mathrm{M})$

and number of animals per hectare on the total area involved in the rotation ( $\mathrm{Sr}$ ).

These relationships are:

Rotation length $=\mathrm{A} / \mathrm{a} \times \mathrm{t}$

$$
\begin{aligned}
& \mathrm{SR} \quad=\mathrm{M} / \mathrm{A} \\
& \text { nt } \quad=M / a \times t \\
& \text { nt } \quad=\mathrm{SR} \times \text { Rotation length }
\end{aligned}
$$


TABLE 1: M inimum pre-grazing mass at which ewes stocked at $n$ ewes/ha will achieve maximum intake of $2 \mathrm{~kg} \mathrm{GDM} / \mathbf{h d} /$ day on the first day of grazing a break $(\mathbf{k}=\mathbf{0 . 0 0 1 1 5})$.

\begin{tabular}{cc}
\hline $\begin{array}{c}\text { Stocking } \\
(\mathrm{n} \text { ewes/ha) }\end{array}$ & Pre-grazing \\
\hline 800 & 2660 \\
750 & 2595 \\
700 & 2530 \\
650 & 2470 \\
600 & 2410 \\
550 & 2345 \\
500 & 2290 \\
450 & 2230 \\
400 & 2170 \\
350 & 2110 \\
300 & 2055 \\
250 & 2000 \\
200 & 1950 \\
150 & 1895 \\
100 & 1840 \\
\hline
\end{tabular}

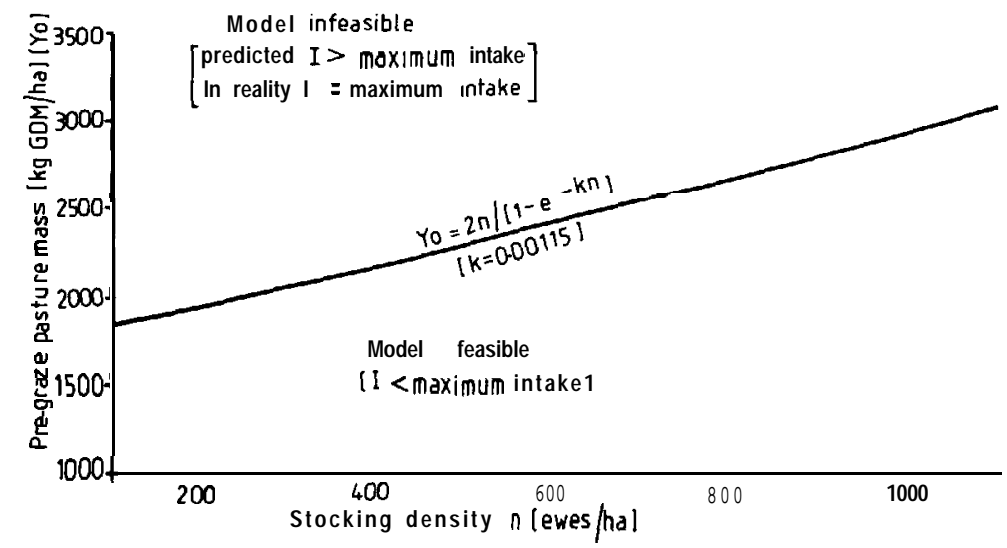

FIGURE 2: M aximum pre-grazing mass values at each stock density consistent with the model and a maximum intake of $2 \mathrm{Kg} \mathbf{G D M} / \mathbf{h} / \mathbf{d}(\mathrm{k}=0.00115)$.

\section{Pre-grazing mass effects on intake}

Shifting ewes when they have grazed to a given pasture residual (eg. Milligan, 1981) has received widespread attention as a means of controlling their intakes. The model was therefore used to evaluate ewe intakes at a range of pre-grazing pasture masses using this type of decision rule.

The results presented in Table 2 were derived for the decision rule: shift ewes when residual $=400 \mathrm{~kg}$ GDM $/ \mathrm{ha}$.

Values of nt in Table 2 represent the grazing pressure (in ewe grazing days per hectare) required to achieve a residual of $400 \mathrm{~kg}$ GDM/ha from the given pre-graze pasture mass $\left(Y_{0}\right)$. 
ie.

therefore

and
$\mathrm{Y}_{\mathrm{t}}=400$

$400=Y_{0} e^{-k n t}$

$\mathrm{ADI}=(\mathrm{Yo} \cdot \mathrm{Yt}) \mathrm{nt}$

nt $\quad=\left(\ln \mathrm{Y}_{0} \ln 400\right) / \mathrm{k} \ldots . . .5$

where In is the natural logarithm.

The feature of Table 2 is the way in which average daily intake (ADI) varies according to the level of pre-grazing pasture mass. For example over the range of pre-grazing masses 2500 to 1000 , ADI per ewe ranged from 1.32 to $0.75 \mathrm{~kg}$ GDM where residual was a constant $400 \mathrm{~kg}$ GDM/ha. Clearly, if the model describes grazing dynamics adequately, the grazing management rule: shift stock when residual GDM = 400 , will give varying levels of ADI depending on pre-grazing pasture mass. Since the objective of such a grazing management rule is to control animal intake, due regard must be given to pre-grazing pasture mass in setting target residual dry matter levels.

The second point from Table 2 is that each pre-graze mass residual combination can only be achieved by one grazing pressure (nt) and hence rotation length. For example in Table 2 where $Y_{0}=2000$ and a residual of 400 is required, according to the model this requires a grazing pressure of 1400 ewe grazing days/ha. At an overall stocking rate of 17.5 ewes/ha this represents a rotation length of 80 days, $=1400 / 17.5$. Such a rotation length and the resultant AD1 could be achieved by, for example, grazing 200 ewes/ha for 7 days duration, 350 ewes/ha for 4 days duration, 470 ewes/ha for 3 days duration or 1400 ewes/ha for 1 day duration. However, given the assumption about zero pasture growth during the grazing duration, the stocking density ( $\mathrm{n}$ min) should probably not be less than 350 ewes/ha (ie. $t \quad 4$ days) in this situation, to achieve the required intake and residual.

TABLE 2: Relationship between average daily intake and pre-graze pasture mass, given residual equals $400 \mathrm{~kg}$ GDM/ha.

\begin{tabular}{cccc}
\hline $\begin{array}{c}\text { Pre-graze } \\
\left(\mathbf{Y}_{\mathbf{0}}\right)\end{array}$ & $\begin{array}{c}\text { ADl } \\
\mathbf{( k g ~ G D M} / \mathbf{h} / \mathbf{d})\end{array}$ & $\begin{array}{c}\text { Grazing Pressure } \\
(\mathbf{n t})\end{array}$ & $\begin{array}{c}\text { Minimum Stocking } \\
\text { Density }\end{array}$ \\
\hline 3000 & 1.48 & $\mathbf{m i n})$ \\
2700 & 1.39 & 1752 & $1050^{\prime}$ \\
2500 & 1.32 & 1660 & $850^{\prime}$ \\
2200 & 1.21 & 1592 & $700^{\prime}$ \\
2000 & 1.14 & 1482 & $450^{1}$ \\
1800 & 1.07 & 1400 & $350^{2}$ \\
1500 & 0.96 & 1308 & $330^{2}$ \\
1200 & 0.84 & 1149 & $290^{2}$ \\
1000 & 0.75 & 955 & $240^{2}$ \\
\end{tabular}

'Minimum stocking density required to ensure intake on the first day is4 $2.0 \mathrm{~kg}$ GDM (see assumptions and Table 1).

*Minimum stocking density for a maximum grazing duration of 4 days (ie. $t(\max ) \leq 4$ ) see text.

\section{Achieving Target Intakes}

The model can also be used to predict conditions necessary to achieve any target ADI (average daily intake).

$$
\mathrm{AD} 1=\left(\mathrm{Y}_{0} \cdot \mathrm{Y}_{\mathrm{t}}\right) / \mathrm{nt}
$$

$$
=Y_{0}\left(1 \cdot e^{-k n t}\right) / n t \ldots \ldots 6
$$

Thus for any required $\mathrm{ADI}$ and given grazing pressure (nt) the necessary pre-grazing mass is:

$$
\mathrm{Y}_{0}=(\mathrm{ADI} \times \mathrm{nt}) /\left(1 \cdot \mathrm{e}^{-\mathrm{knt}}\right) \quad \ldots \ldots \ldots \ldots
$$

and the residual $\mathrm{GDM} / \mathrm{ha}$ will be given by: 


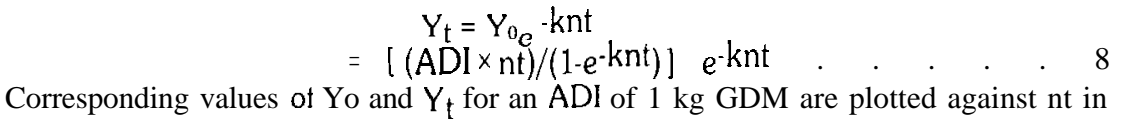
Figure 3.

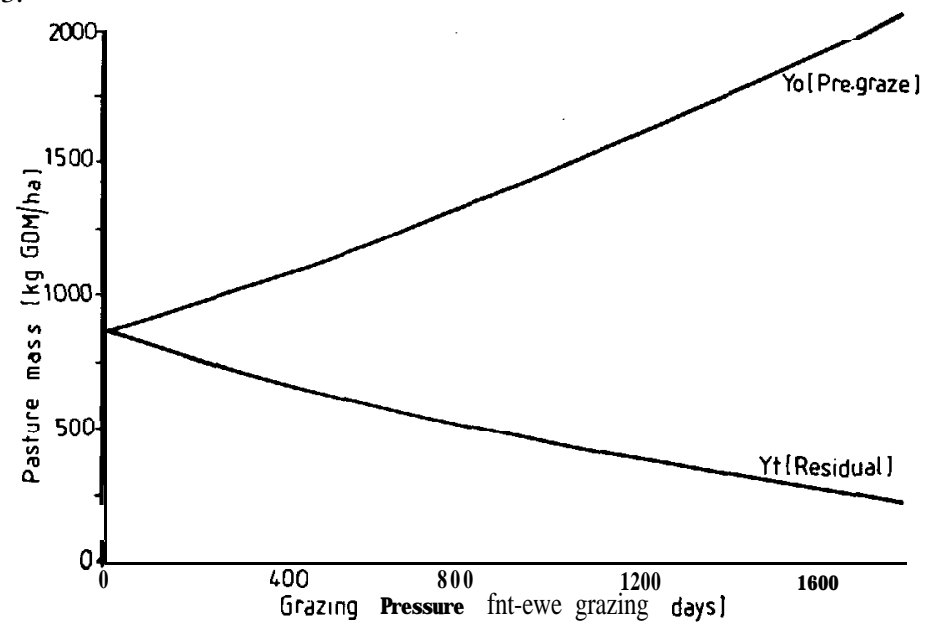

FIGURE 3: Combinations of pre-and post-grazing pasture mass and grazing pressure which result in $\mathrm{ADI}=1.0$.

Figure 3 illustrates the interdependencies among variables in the grazing situation. For the given ADI, pre-grazing mass increases and post-grazing mass decreases as grazing pressure increases. However if target ADI is $1 \mathrm{~kg}$ GDM/ewe and target residual is $400 \mathrm{~kg} \mathrm{GDM} / \mathrm{ha}$, then these targets can only be met simultaneously if pre-grazing mass is $1600 \mathrm{~kg} \mathrm{GDM} / \mathrm{ha}$ and $\mathrm{nt}=1200$ ewe grazing days $/ \mathrm{ha}$. Conversely if $\mathrm{nt}=1200$ then the ewes will need to go on to $1600 \mathrm{~kg} \mathrm{GDM} / \mathrm{ha}$ to achieve an intake of 1.0 and the residual will equal $400 \mathrm{~kg} \mathrm{GDM} / \mathrm{ha}$.

Finally, since $t \max$ has been assumed to be 4 days in our zero pasture growth model, stocking 6 ensity (n) should probably be at least 400 ewes/ha in the example above. Where grazing duration is longer than 4 days and at times of the year when pasture growth rates are high, pasture growth rate should also be accounted for in predicting ADI (eg. Bircham et al. 1985).

\section{Feed budgeting accuracy}

The model was finally used to investiage the likely magnitude of errors associated with using a simple feed budgeting approach to assess time spent grazing a paddock. In the example chosen, mob and paddock sizes were assumed such that $n=400$. Target values for $\mathrm{AD} 1$ and residual were set at 1.0 and 400 , respectively. If pre-grazing mass is 2000 then a simple feed budget would give a grazing duration oft $=4$ days to meet these criteria. The model can be used to predict actual ADI and residual.

Table 3 shows results of applying simple feed budgeting rules to determine grazing duration. In this example the feed budget only works where Yo $=1600$. The cost of the errors where Yo does not equal 1600 can only be assessed in terms of the opportunity cost of not achieving the target ADI or residual. Where Yo $>1600$ opportunity costs to be considered are those of underfeeding the ewes and having higher residuals than budgeted. Where $Y_{0}<1600$ the errors to be considered relate to the cost of overfeeding and having lower residuals than budgeted. 
TABLE 3: Results of applying simple feed budgeting rules to determine grazing duration $(n=400$, target $A D \mid=1$, target residual $=400$ ).

\begin{tabular}{cccc}
\hline $\begin{array}{c}\text { Pre-graze mass } \\
\text { (kg GDM/ha) }\end{array}$ & $\begin{array}{c}\text { Grazing Duration } \\
\text { (days) }\end{array}$ & $\begin{array}{c}\text { Residual Mass } \\
\text { (kg GDM/ha) }\end{array}$ & $\begin{array}{c}\text { ADI } \\
\text { (kg GDM/ewe) }\end{array}$ \\
\hline 2000 & 4 & 318 & 1.05 \\
1600 & 3 & 402 & 1.00 \\
1200 & 2 & 478 & 0.90 \\
800 & 1 & 505 & 0.74 \\
\hline
\end{tabular}

\section{DISCUSSION}

Analyses conducted using the simple pasture disappearance model presented in this paper clearly show the interdependence between intake, pre-and post-grazing pasture mass and grazing pressure in the grazing situation. Pre-graze green pasture mass has a big effect on intake when stock are grazed to a common residual. The implication is that where the objective of grazing management is to control intake, attention must be paid to pre-grazing mass in setting target residuals. As a result of the effects of pre-graze as well as residual mass on intake, there are likely to be errors associated with using the simple feed budgeting approach to predict the achievement of a given intake. The importance of these errors will depend on the opportunity costs of under or over feeding the stock by as much as $0.25 \mathrm{~kg} \mathrm{GDM} / \mathrm{h} /$ day in some situations.

Intake as described by the model is governed by green pasture mass and hence accessibility. Green mass/intake relationships have been shown to be very similar in pastures with widely differing structures (e.g. winter vs summer) (Bircham et al. 1985). At equal pre-graze masses a high stocking density decreases the mass challenging the individual (and hence intake), faster than a low stocking density and hence results in a lower intake by the former for that day. However, when grazing to a given residual, ewes on high pre-graze pasture masses at high stocking densities spend a smaller percentage of their total grazing duration grazing on pasture masses which severely limit intake compared to those grazing low pre-graze mass pastures. This is the reason for higher intakes being achieved where pre-graze masses are high, despite residuals being the same.

The relationships presented in this paper provide a simple means of integrating the factors affecting intake for practical application, given a suitable calculator. Alternatively, appropriate pre-grazing masses, residuals or grazing pressures to achieve target ADl's can easily be assessed where the other two variables are given, using graphical output from the above model as in Figure 3. However caution needs to prevail when using the model to determine time spent grazing a paddock or grazing pressure (nt) to achieve a target ADI based on the pre-graze mass in the paddock. In the whole-farm situation we need to consider what is feasible in terms of different ADI levels over a longer time period, particularly over winter. Pasture growth over winter may not support the chosen ADI for a particular stocking rate. Secondly pasture cover may be so low at the start of winter that it requires too fast a rotation in order to try and support our ADI. What is feasible in terms of ADI levels over winter, and the implications for autumn, winter and spring management, can really only be investigated in the context of a whole farm model which includes a pasture growth component.

\section{REFERENCES}

Bircham, J. S.; Sheath, G. W.; Boom, R. C. 1985. NZ J agric Res (in press)

Hodgson, J. 1975. Proc. Brit Grassids Soc., Occ Pub. No. 8: 93.103.

Milligan, K. E. 1981. In: "Grazing Management" Section 5, Supplement to New Zealand Farmer, December 10, 1981

Rattray, P. V.; Clark, D. A. 1984. N.Z. J. agric Sci. 18: 141.146

Sheath, G. W. 1983. N.Z. J. Exp. Ag. 11:309-319. 